\title{
Leukocyte Count, CRP and Bilirubin Level in Complicated and Non-Complicated Appendicitis: Cross Sectional Study
}

\author{
Zejnullahu VA', Krasniqi $A^{1}$, Isjanovska $R^{3}$, Bicaj \\ BX $^{1}$, Zejnullahu VA ${ }^{1}$, Hamza AR $^{1}$ and Caloska- \\ Ivanova $\mathrm{V}^{2 *}$ \\ ${ }^{1}$ Department of Abdominal Surgery, University Clinical \\ Centre of Kosova, Kosovo \\ ${ }^{2}$ Department of Gastroenterohepatology, Ss Cyril and \\ Methodius University of Skopje, Macedonia \\ ${ }^{3}$ Agency for Quality and Accreditation of Healthcare \\ Organizations in R. Macedonia, Research Fields: Public \\ Health, Health Policies, Health Care Management, \\ Quality and Accreditation, Macedonia \\ *Correspondling author: Caloska-Ivanov V, \\ Department of Gastroenterology, University Clinical \\ Center of Skopje, Skopje, Republic of Macedonia
}

Received: August 21, 2017; Accepted: October 24, 2017; Published: October 31, 2017

\begin{abstract}
Background: Undoubtedly, one of the most frequently observed pathology in abdominal surgery is appendicitis, which presents a diagnostic challenge for the majority of general surgeons during their work, regardless of several diagnostic modalities applied.
\end{abstract}

Aim: The purpose of this study is to evaluate the difference of hyperbilirubinemia, CRP value and leukocyte count in the early diagnosis between the complicated and non- complicated cases of appendicitis.

Materials and Methods: This is a cross sectional study, that was conducted at the University Clinical Center of Prishtina in the Department of Abdominal Surgery in patients admitted with clinical signs of appendiceal inflammation during the period from September 2016 to March 2017. Total number of 91 patients was included in the study. All participants were subjected to the bilirubin level determination, leukocyte count and CRP value determination along with diagnostic, hepatic transaminases and Alvarado score.

Results: The total number of 91 patients with diagnosis of appendicitis acute was involved in this study. The laboratory markers was measured preoperatively for all patients divided in two groups group with complicated appendicitis and group without complication. From the total number of patients $53.8 \%$ were male and $45.1 \%$ were female. The percentage difference between genders is statistically insignificant $p>0.05$. In our study we measured the level of WBC, serum bilirubin, CRP and liver enzyme (AST and ALT) between two groups of patients. According to the t- test for WBC, CRP and Bilirubin the difference between two groups are statistical significant $(p<0.05)$.

We didn't find any difference in the level of AST and ALT between two groups of study. During this study we conclude that predictor model of Alvarado score is useful clinical approach for diagnosis of appendicitis.

Conclusion: Routine measurement of serumbilirubin, CRP, WBC combined with Alvarado Score model in all patients admitted in emergency ward suspected for appendicitis may decrease the rate of complications in acute appendicitis.

Keywords: Acute appendicitis; Serum bilirubin; Ultrasonography; Leukocyte count; Appendectomy

\section{Abbreviations}

CRP: C - Reactive Protein; WBC: White Blood Cell; MRI: Magnetic Resonance Imaging; CT: Computed Tomography; AIR: Appendicitis Inflammatory Response; PAS: Pediatric Appendicitis Score

\section{Introduction}

The appendix arises from the posteromedial side of the caecum and can be situated in relation to caecum as retrocaecal, pelvic, subcaecal, preileal and in right pericolic area. Summarized findings from Collins in 4,680 appendix postmortal samples, revealed that appendix is placed anteriorly in $50 \%$ of cases while $21.4 \%$ were with retrocecal localization.
Appendicitis is one of the most common surgical disorders and the cause of emergency surgery on children and in adult ages. Up to $40 \%$ of cases occur in the age-group between 10 and 29 years [1]. Common cause of appendicitis is usually obstruction of lumen with nonspecific factors $[2,3]$. This obstruction occurs from the undigested food, fecaloma, from lymphoid inflammation or even any twist around this organ can be a reason for obstruction.

Escherichia coli and Bacteroides fragilis comprises two organisms which are equally presented in normal appendix as well as in acute and perforated appendicitis $[4,5]$. Studies in animal models showed that bacteria can interfere with microcirculation on the hepatocyte, thus inducing hepatic damage with impaired acid bile secretion within the hepatobiliary system [6] E. coli affects also the intravascular hemolysis, second mechanisms by which bilirubin levels increases in
Austin J Surg - Volume 4 Issue 3 - 2017

ISSN : 2381-9030 | www.austinpublishing group.com

Caloska-Ivanova et al. (@) All rights are reserved
Citation: Zejnullahu VA, Krasniqi A, Isjanovska R, Bicaj BX, Zejnullahu VA, Hamza AR, et al. Leukocyte Count, CRP and Bilirubin Level in Complicated and Non-Complicated Appendicitis: Cross Sectional Study. Austin J Surg. 2017; 4(3): 1106 


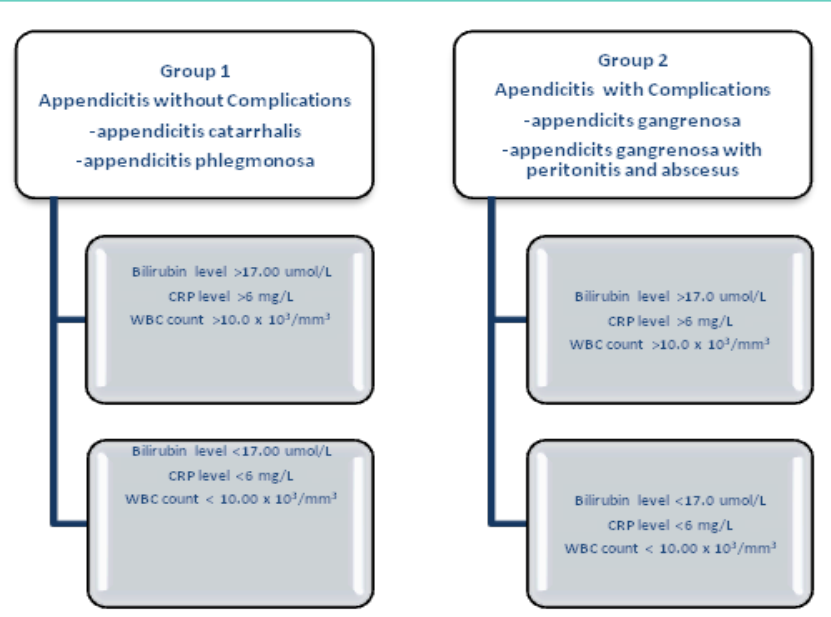

Figure 1: Complicated appendicitis versus the group of patients with noncomplicated appendicitis.

the blood circulation [7]. Although, it is frequently seen between the second to the fourth decade of life, it can be diagnosed in any given age. Referring to the previous studies appendicitis is more frequent in males compared to females $(8.6 \%$ vs. 6.7\%) [8]. The mortality rate for acute appendicitis with treatment is reported to be less than $1 \%$, high rate of negative appendectomy in children and the constant rate of misdiagnosis up to $15.3 \%$ make this condition the diagnostic challenge for the majority of general surgeons during their work [1]. In view of this, it is of crucial importance to decide whether patients need urgent surgery or expectative management may be applied in cases where symptomatology is obscure and further examinations are required. The newest strategy in treatment of uncomplicated acute appendicitis is treatment with antibiotic therapy reserved in early stage of inflammation. From this point of view it is very important to decide whether the conservative approach needs to change in to operative management. Some previous study suggesting for different pattern of treatment between perforated and non-perforated appendicitis [9]. The diagnosis of acute appendicitis and decision when to preformed operation are challenge for any surgeon. Many scoring system are proposed starting from the first score which was presented by Alvarado in 1986 and furthermore modified Alvarado score was presented by Kalan and colleagues [10]. Their score ranged from 0-9 points and include symptoms, signs and laboratory markers. In Sweden, the Appendicitis Inflammatory Response (AIR)-score was presented in 2008 [11]. Adult appendicitis score was presented by Sammalkorpi and colleagues, recently [12]. Concerning the pediatric population two scores are used namely the Pediatric Appendicitis Score (PAS) [13] and the Lintula score [14]. Clinical examination combine with imagery and laboratory markers facilitates the diagnosis and decision for treatment. Early periumbilical pain in appendicitis is conditioned by sympathetic nerve supply and distention of the visceral peritoneum and furthermore, thoracic sensory response because of the parietal peritoneum inflammation, leads to the pain in the right ileocecal region.

Graded compression ultrasound scan for the diagnosis of acute appendicitis, was described for the first time in 1986 by Puylaert [15]. Ultrasound scan alone has a sensitivity of $86 \%$, a specificity of $95 \%$ and an accuracy of $92 \%$ [16]. Evidence provided by Kaneko and
Tsuda showed that ultrasound scan can identify patients who need immediate surgery and enable conservative treatment for mild cases [17]. According to Balthazar and colleagues, computed tomography showed a higher accuracy in the diagnosis of acute appendicitis compared to ultrasound [18]. Another diagnostic modality used in diagnosis of acute appendicitis comprises MRI, which when used as primary diagnostic tool revealed a sensitivity of $96.8 \%$ and specificity of $97.4 \%$ [19]. The methods such computed tomography and MRI are very expensive and even can delay the diagnosis; especially this method is not available in country with low outcomes.

Laboratory test are very important in diagnostic evaluation of acute appendicitis. Besides the test such is WBC count with differential, serum C Reactive Protein (CRP), and pregnancy test for women of childbearing age, recently several studies focused their attention on the elevated serum bilirubin as a low cost and useful laboratory marker in clinical settings for the diagnosis of the complicated appendicitis. Hyperbilirubinemia was found in $87 \%$ of patients with acute appendicitis [20] while in the retrospective study from Sand and colleagues total serum bilirubin was found to be much higher in gangrenous/perforative appendicitis [21]. This paper among many studies is willing to assess whether hyperbilirubinemia together with WBC count and CRP can serve as the primary diagnostic tool in the early diagnosis of appendicitis and to distinguish the complicated from non-complicated acute appendicitis. The operative treatment includes open surgery and laparoscopic appendectomy.

\section{Aim of the Study}

The overall aim of this study is to serially compare the laboratory markers between the groups of patients with complicated appendicitis versus the group of patients with non-complicated appendicitis admitted in the emergency ward (Figure 1).

\section{Materials and Methods}

\section{Study Design}

The cross sectional study, was conducted in the University Clinical Center of Prishtina in the Department of Abdominal Surgery and in the General Hospital of Mitrovica in patients admitted with clinical signs of appendicitis during the period of time from September 2016 to March 2017.

\section{Study sample}

A total number of 91 patients admitted in the Emergency ward with abdominal pain, suspicious for acute appendicitis are included in this study after initial workup.

\section{Inclusion criteria}

1. Patients admitted in emergency ward clinically suspicious for acute appendicitis.

2. Patients from 14 years old and above.

\section{Exclusion criteria}

1. Children with abdominal pain younger than 14 years.

2. Patients with liver disease and jaundice.

3. Patients with hemolytic anemia and consequent hyperbilirubinemia. 
Table 1: View of values between complicated and non-complicated.

\begin{tabular}{|c|c|c|}
\hline appendicitis & Count & Percent \\
\hline complicated & 60 & 65.9 \\
\hline non-complicated & 31 & 34.1 \\
\hline Total & 91 & 100 \\
\hline
\end{tabular}

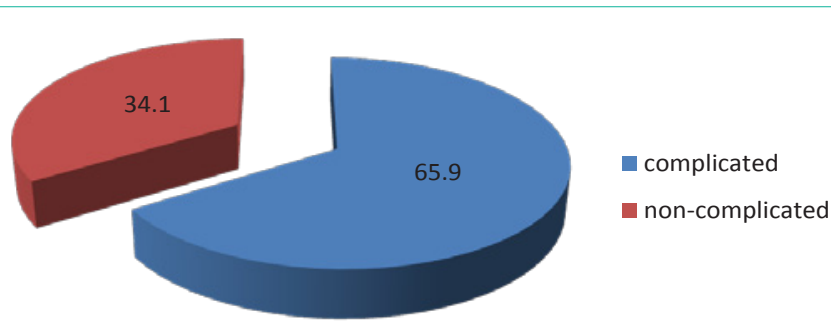

Graph 1:

4. Patients with abdominal trauma injury.

\section{Data collection}

Informed consent was provided by all subjects participating in this study which was also ethically approved. Specifically designed questionnaire for age, gender, weight, height and evaluation form of patient clinical assessment were filled from each subject before proceeding with the study.

In all subjects the blood samples was taken by venipuncture for leucocyte count estimation (expressed as cells/liter) and CRP (expressed as $\mathrm{mg} / \mathrm{L}$ ) and for total and direct bilirubin. WBC equal and greater than $10 \times 10^{9}$ and a CRP greater than $6 \mathrm{mg} / \mathrm{L}$ are deemed positive respectively pathological. Direct bilirubin $>5.1 \mathrm{umol} / \mathrm{L}$ and total bilirubin $>18.8 \mathrm{umol} / \mathrm{L}$ are reference values. Blood samples was collected after initial clinical workup.

Other variables include level of AST and ALT markers, Alvarado score algorithm and postoperative histopathological analysis of all patient samples.

In this part of the study we have been able to analyze 91 patients admitted in the emergency ward in which we preformed laboratory measurement of Leukocyte, CRP, Bilirubine level, AST and ALT level.

\section{Results}

This cross sectional study was conducted in the University Clinical Center of Prishtina in the Department of Abdominal Surgery in all patients admitted with clinical signs of appendiceal inflammation in emergency department during the period of time from September 2016 to March 2017. The diagnosis of acute appendicitis was confirmed by clinical examination using Alvarado score, ultrasound examinations and laboratory markers such as Leukocyte count, CRP, Bilirubin, and AST, ALT.

The total number of 91 patients with appendicitis was involved in the study, of whom $53.8 \%$ were male and $45.1 \%$ were female, and they

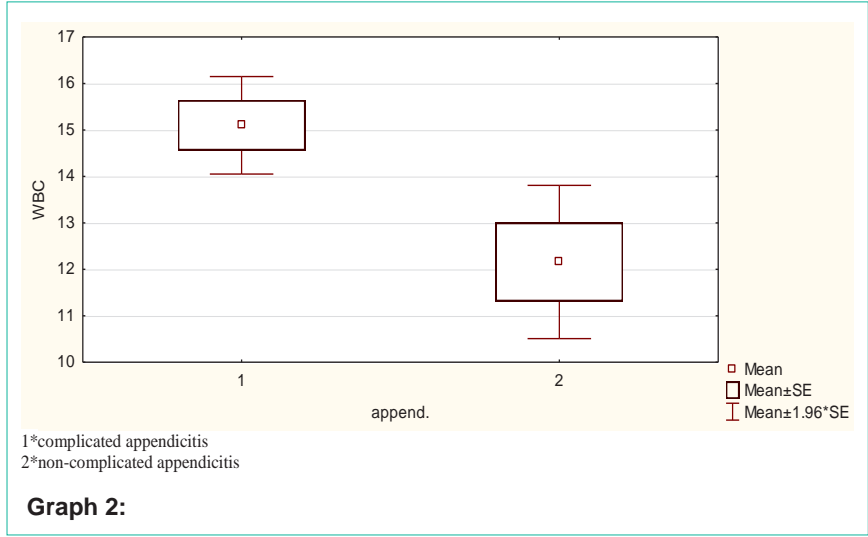

were divided in two groups with complicated and non-complicated appendicitis (Table 1 and Graph 1).

The average level of WBC of patients from the examined complicated appendicitis group is $14.1 \mathrm{~g} / \mathrm{l}$, which is above the reference values $(4.0-10.0 \mathrm{~g} / \mathrm{l})$. The average level of WBC of patients from the examined non-complicated appendicitis group is $12.2 \mathrm{~g} / \mathrm{l}$, which is above the reference values $(4.0-10.0 \mathrm{~g} / \mathrm{l})$. According t-test the difference between two groups are statistical significant for $\mathrm{p}<0.05$ (Table 2 and Graph 2).

The average level of total bilirubin level for patients from the examined complicated appendicitis group is $27.4 \mu \mathrm{mol} / \mathrm{l}$, which is above the reference values $(3.4-18.8 \mu \mathrm{mol} / \mathrm{l})$. The average level of total bilirubin for patients from the examined non-complicated appendicitis group is $14.64 \mu \mathrm{mol} / \mathrm{l}$, which is within limits of reference values (3.4-18.8 $\mu \mathrm{mol} / \mathrm{l})$ (Table 3 and Graph 3a).

According the Mann-Whitney U Test the difference between two groups are statistical significant for $\mathrm{p}<0.05$ (Table 4).

The average level of direct bilirubin in patients from the examined complicated appendicitis group is $8.3 \mu \mathrm{mol} / \mathrm{l}$, which is above the reference values, (up to $5.1 \mu \mathrm{mol} / \mathrm{l}$ ) (Table 3 and Graph 3a). The average level of direct bilirubin in patients from the examined non-complicated appendicitis group is $4.4 \mu \mathrm{mol} / \mathrm{l}$, which is smaller than reference values, (up to $5.1 \mu \mathrm{mol} / \mathrm{l}$ ) (Table 3 and Graph 3a). According the Mann-Whitney U Test the difference between two groups are statistical significant for $\mathrm{p}<0.05$ (Table 4 ).

The average level of CRP for patients from the examined complicated appendicitis group is 95.5 which are above the reference values (up to 6). The average level of CRP for patients from the examined non-complicated appendicitis group is 48.75 which are above the reference values (up to 6) (Table 3 and Graph 3b). According the Whitney $\mathrm{U}$ Test the difference between two groups are statistical significant for $\mathrm{p}<0.05$ (Table 4 ). In our study there are no differences in level of liver enzyme for AST and ALT between two groups of appendicitis (Table 4).

Table 2: WBC Count.

\begin{tabular}{|c|c|c|c|c|c|c|c|c|}
\hline Mean - 1 & Mean - 2 & t-value & df & P & Valid N - 1 & Valid N - 2 & Std.Dev. - 1 & Std.Dev. - 2 \\
\hline 15.1 & 12.15806 & 3.073267 & 88 & 0.002819 & 59 & 31 & 4.111548 & 4.684355 \\
\hline
\end{tabular}


Table 3: View of average values of the laboratory parameters.

\begin{tabular}{|c|c|c|c|c|c|}
\hline Complicated app. & Valid N & Mean & Minimum & Maximum & Std.Dev. \\
\hline Bil Level T & 59 & 27.4 & 3.7 & 119.1 & 23.31865 \\
\hline Bil Level D & 59 & 8.3 & 1.7 & 90.2 & 11.48389 \\
\hline CRP & 60 & 95.5 & 6 & 360 & 74.11125 \\
\hline AST & 60 & 22.9 & 7 & 78 & 11.78924 \\
\hline ALT & 60 & 22.3 & 6 & 56 & 10.68124 \\
\hline non-complicated app & Valid N & Mean & Minimum & Maximum & Std.Dev. \\
\hline Bil Level T & 31 & 14.6 & 4.9 & 40 & 7.64321 \\
\hline Bil Level D & 31 & 4.4 & 1.3 & 11.9 & 2.13231 \\
\hline CRP & 30 & 48.7 & 0.17 & 425.63 & 78.63301 \\
\hline AST & 31 & 23.2 & 10 & 56 & 11.40006 \\
\hline ALT & 31 & 23.8 & 11 & 58 & 9.82547 \\
\hline
\end{tabular}
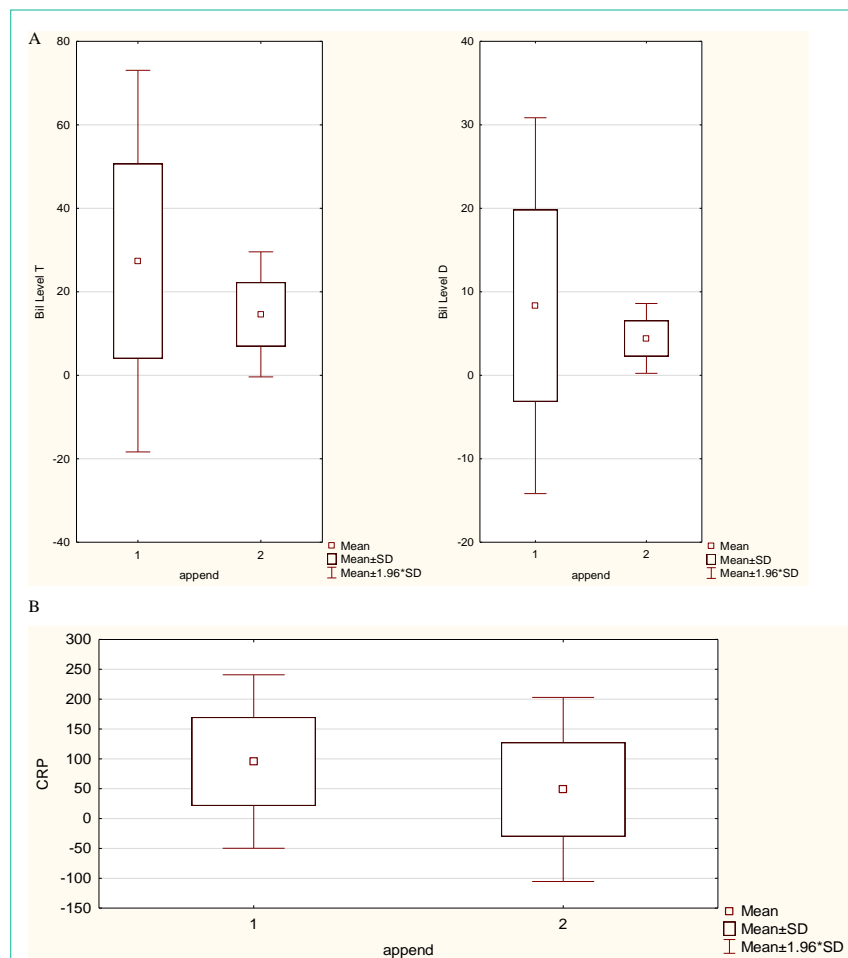

C
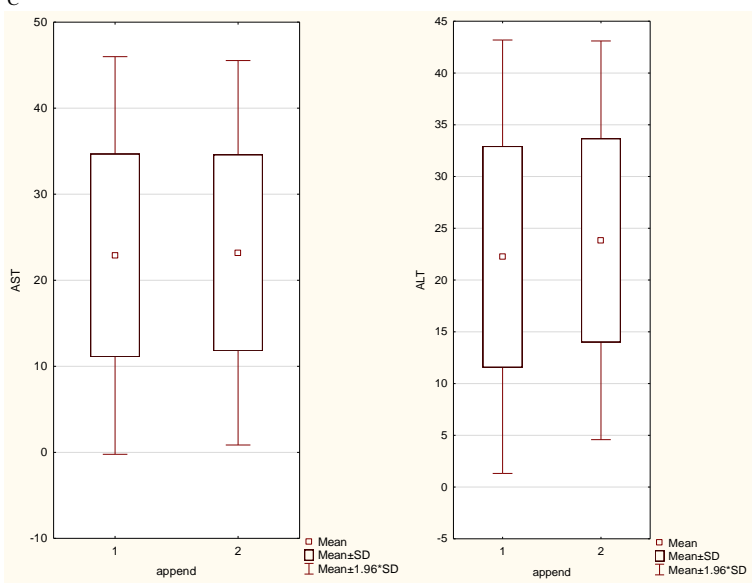

Graph 3:

Table 4: Mann-Whitney U test.
\begin{tabular}{|c|c|c|c|c|c|}
\hline & $\begin{array}{c}\text { Rank Sum - } \\
\text { Group 1 }\end{array}$ & $\begin{array}{c}\text { Rank Sum - } \\
\text { Group 2 }\end{array}$ & U & Z & p-value \\
\hline $\begin{array}{c}\text { Bil Level } \\
\text { T }\end{array}$ & 3080.5 & 1014.5 & 518.5 & 3.35822 & 0.000785 \\
\hline $\begin{array}{c}\text { Bil Level } \\
\text { D }\end{array}$ & 3129.5 & 965.5 & 469.5 & 3.77429 & 0.00016 \\
\hline CRP & 3202.5 & 892.5 & 427.5 & 4.03995 & 0.000053 \\
\hline AST & 2736.5 & 1449.5 & 906.5 & -0.19261 & 0.847268 \\
\hline ALT & 2630 & 1556 & 800 & -1.08445 & 0.278166 \\
\hline
\end{tabular}

$1{ }^{*}$ complicated appendicitis

2*non-complicated appendicitis

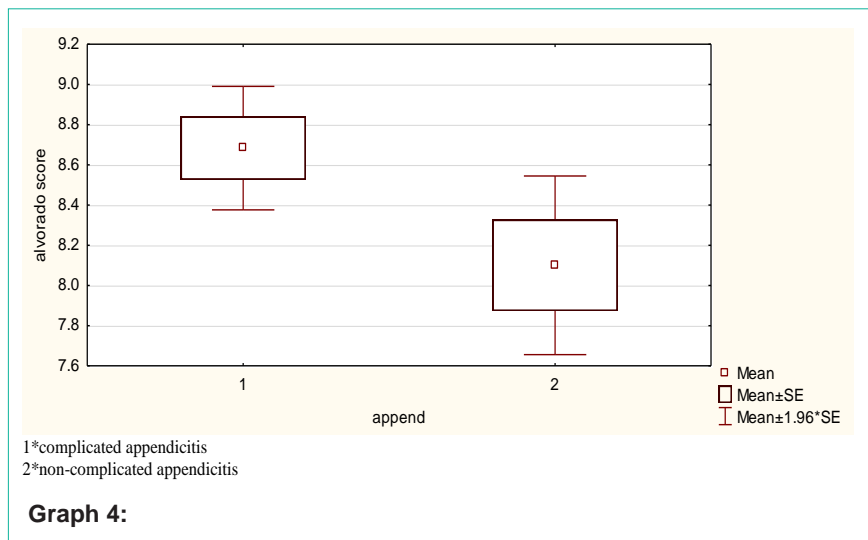

Table 5: View of the Alvarado score.

\begin{tabular}{|l|l|l|l|l|l|}
\hline Mean - 1 & Mean - 2 & Valid N - 1 & Valid N - 2 & Std.Dev. - 1 & Std.Dev. - 2 \\
\hline
\end{tabular}

\begin{tabular}{|l|l|l|l|l|l|}
\hline 8.7 & 8.1 & 60 & 30 & 1.214205 & 1.241523 \\
\hline
\end{tabular}

$1{ }^{*}$ complicated appendicitis

$2^{*}$ non-complicated appendicitis

The predictor model of the Alvarado Score during clinical examination was statistically significant. This shows that Alvarado score was useful during clinical diagnosis for acute appendicitis (Table 5 and Graph 4).

\section{Discussion}

Appendicitis is one of most frequent surgical interventions preformed in abdominal surgery. The correct diagnosis and intervention before the complication is important and challenge for general surgeon.

In this study we intended to analyze the gender difference between male and female patients, laboratory markers such WBC, CRP, Bilirubin level, AST and ALT for all patients admitted in emergency ward in which surgical team preformed appendectomy.

In this study we analyzed 91 patients with complicated and no complicated acute appendicitis. From the total number, 53.8\% were male and while $45.1 \%$ female and this difference between two groups is statistically insignificant $\mathrm{p}>0.005$.

According to the study performing from Stein GY and al male patients are more affected from acute appendicitis than females [22].

Several scoring system are used in the clinical evaluation for acute appendicitis. In our study we analyzed clinical manifestation based on Alvarado Score algorithm were we found that $54.9 \%$ of patients with definitive diagnosis based on Alvarado Score have undergone surgical intervention. 
From all 91 patients divided in two groups were we analyzed WBC level, according to the $t$ test the difference are statistical significant for $\mathrm{p}<0.05$.

These are similar results with the previous study were the level of white blood cell count was found to be elevated in 80 percent of patients diagnosed with acute appendicitis [23].

In two groups of patients we preformed measured of serum bilirubin and we found that average level of total bilirubin were $14.64 \mathrm{umol} / \mathrm{l}$ and based on the Mann-Whitney U Test the difference between two groups are statistical significant $(\mathrm{p}<0.05)$. Referring the same studies from different countries these results are similar to other studies, were elevated levels of bilirubin are corresponding with complicated appendicitis such perforation and peritonitis [24,25].

In the group of complicated appendicitis, the average level of CRP is 95.5 above the reference (cut off up to 6). In non-complicated group of appendicitis the average level of CRP is 48.75 and according to the Whitney $\mathrm{U}$ test there is difference with statistical significance with $\mathrm{p}<0.05$. Referring to different studies for appendicitis there are different results about CRP value in acute appendicitis and its complications some of them authors conclude that appendicitis is not common in absence of elevation of WBC and CRP [26] while other studies shows cases were appendicitis is present despite the normal range of CRP [27]. The amount of AST and ALT values were within limits for most patients in our study.

The percentage of $35.2 \%$ of the patients is comprised of patients with acute appendicitis, and lastly, the percentage of $8.8 \%$ consists of patients with a possible diagnosis of acute appendicitis in accordance with the Alvarado Score. Several studies have shown that the accuracy of Alvarado Score is $99 \%$ in the level were cut-point is 5 or more [28]. This is consistent with the results of this study.

\section{Conclusion}

The findings from this study suggest that preoperatively assessment of Bilirubin, CRP, WBC and Alvarado scoring system together like routine procedure for patients admitted in the emergency ward, may help the surgeon to determinate the risk of complications in the acute appendicitis. According to our study for all patients with clinical signs of appendicitis the routine measured of serum bilirubin, CRP and WBC level can distinguish complicated from non-complicated cases of appendicitis. This will help surgeon to decide whether to preformed operation or to start with conservative treatment for patient with suspicion for acute appendicitis. This may decrease the rate of complications especially in the country was CT scanning is expensive and difficult to reach.

\section{References}

1. Schwartz SI, Brunicardi FC. Schwartz's principles of surgery. New York: McGraw-Hill, Medical Pub. Division; 2010. xxi, 1866; $9^{\text {th }}$ edn.

2. Bundy DG, Byerley JS, Liles EA, Perrin EM, Katznelson J, Rice HE. Does this child have appendicitis? JAMA. 2007; 298: 438-451.

3. Rabah R. Pathology of the appendix in children: an institutional experience and review of the literature. Pediatr Radiol. 2007; 37: 15-20.

4. Rautio M, Saxen H, Siitonen A, Nikku R, Jousimies-Somer H. Bacteriology of histopathologically defined appendicitis in children. Pediatr Infect Dis J. 2000; 19: 1078-1083.
5. Kokoska ER, Silen ML, Tracy TF, Dillon PA, Kennedy DJ, Cradock TV, et al. The impact of intraoperative culture on treatment and outcome in children with perforated appendicitis. J Pediatr Surg. 1999; 34: 749-753.

6. Rink RD, Kaelin CR, Giammara B, Fry DE. Effects of live Escherichia col and Bacteroides fragilis on metabolism and hepatic pO2. Circ Shock. 1981; 8: $601-611$.

7. Shander A. Anemia in the critically ill. Crit Care Clin. 2004; 20: 159-178.

8. Addiss DG, Shaffer N, Fowler BS, Tauxe RV. The epidemiology of appendicitis and appendectomy in the United States. Am J Epidemiol. 1990; 132: 910-925.

9. Andersson R, Hugander A, Thulin A, Nystrom PO, Olaison G. Indications for operation in suspected appendicitis and incidence of perforation. Bmj. 1994; 308: 107-110.

10. Kalan M, Talbot D, Cunliffe WJ, Rich AJ. Evaluation of the modified Alvarado score in the diagnosis of acute appendicitis: a prospective study. Ann R Coll Surg Engl. 1994; 76: 418-419.

11. Andersson M, Andersson RE. The appendicitis inflammatory response score: a tool for the diagnosis of acute appendicitis that outperforms the Alvarado score. World J Surg. 2008; 32: 1843-1849.

12. Sammalkorpi HE, Mentula $P$, Leppaniemi A. A new adult appendicitis score improves diagnostic accuracy of acute appendicitis-a prospective study. BMC Gastroenterol. 2014; 14: 114.

13. Samuel M. Pediatric appendicitis score. J Pediatr Surg. 2002; 37: 877-881.

14. Lintula H, Pesonen E, Kokki H, Vanamo K, Eskelinen M. A diagnostic score for children with suspected appendicitis. Langenbecks Arch Surg. 2005; 390: 164-170.

15. Puylaert JB. Acute appendicitis: US evaluation using graded compression. Radiology. 1986; 158: 355-360.

16. Kaiser S, Mesas-Burgos C, Soderman E, Frenckner B. Appendicitis in children-impact of US and CT on the negative appendectomy rate. Eur J Pediatr Surg. 2004; 14: 260-264.

17. Kaneko K, Tsuda M. Ultrasound-based decision making in the treatment of acute appendicitis in children. J Pediatr Surg. 2004; 39: 1316-1320.

18. Balthazar EJ, Birnbaum BA, Yee J, Megibow AJ, Roshkow J, Gray C. Acute appendicitis: CT and US correlation in 100 patients. Radiology. 1994; 190: 31-35.

19. Kulaylat AN, Moore MM, Engbrecht BW, Brian JM, Khaku A, Hollenbeak CS, et al. An implemented MRI program to eliminate radiation from the evaluation of pediatric appendicitis. J Pediatr Surg. 2015; 50: 1359-1363.

20. Khan S. Elevated serum bilirubin in acute appendicitis: a new diagnostic tool. Kathmandu Univ Med J (KUMJ). 2008; 6: 161-165.

21. Sand M, Bechara FG, Holland-Letz T, Sand D, Mehnert G, Mann B. Diagnostic value of hyperbilirubinemia as a predictive factor for appendiceal perforation in acute appendicitis. Am J Surg. 2009; 198: 193-198.

22. Stein GY, Rath-Wolfson L, Zeidman A, Atar E, Marcus O, Joubran S, et al Sex differences in the epidemiology, seasonal variation, and trends in the management of patients with acute appendicitis. Langenbecks Arch Surg. 2012; 397: 1087-1092.

23. Hardin DM, Jr. Acute appendicitis: review and update. American family physician. 1999; 60: 2027-2034.

24. Chaudhary P, Kumar A, Saxena N, Biswal UC. Hyperbilirubinemia as a predictor of gangrenous/perforated appendicitis: a prospective study. Annals of gastroenterology. 2013; 26: 325-331.

25. Burcharth J, Pommergaard HC, Rosenberg J, Gogenur I. Hyperbilirubinemia as a predictor for appendiceal perforation: a systematic review. Scandinavian journal of surgery: SJS: official organ for the Finnish Surgical Society and the Scandinavian Surgical Society. 2013; 102: 55-60.

26. Sengupta A, Bax G, Paterson-Brown S. White cell count and C-reactive protein measurement in patients with possible appendicitis. Ann R Coll Surg Engl. 2009; 91: 113-115. 
27. Vaughan-Shaw PG, Rees JR, Bell E, Hamdan M, Platt T. Normal inflammatory markers in appendicitis: evidence from two independent cohort studies. JRSM short reports. 2011; 2: 43.
28. Ohle R, O'Reilly F, O'Brien KK, Fahey T, Dimitrov BD. The Alvarado score for predicting acute appendicitis: a systematic review. BMC medicine. 2011; 9: 139
Austin J Surg - Volume 4 Issue 3 - 2017

ISSN : 2381-9030 | www.austinpublishing group.com

Caloska-Ivanova et al. (C) All rights are reserved
Citation: Zejnullahu VA, Krasniqi A, Isjanovska R, Bicaj BX, Zejnullahu VA, Hamza AR, et al. Leukocyte Count, CRP and Bilirubin Level in Complicated and Non-Complicated Appendicitis: Cross Sectional Study. Austin J Surg. 2017; 4(3): 1106 